\title{
Design and Development of Secondary Clarifier for Paper and Pulp Industry with a Case Study
}

\author{
N. Raggul ${ }^{1 *}$ and R. Saraswathi ${ }^{2}$ \\ 'Anna University, Chennai, India; ragguln@gmail.com \\ 2Coimbatore Institute of Technology, Coimbatore India; saraswathi70@rediffmail.com
}

\begin{abstract}
In this paper mathematical models were created using Artificial Neural Network (ANN) for designing the thickener area of the clarifier by correlating the process control parameters, including the mean cell residence time $\left(\theta_{c}\right)$, initial suspended solids concentration $\left(\mathrm{C}_{0}\right)$, underflow concentration $\left(\mathrm{C}_{\mathrm{u}}\right)$, and recycling ratio $(\mathrm{R})$. The test data were applied to the neural network for each value of $\theta_{c}$ and R. A feed-forward ANN model had been proposed to predict the performance of secondary clarifier. The training time was varied between 0.009 and $22 \mathrm{~s}$. The epochs required for the trained feed-forward network varied between 100 and 500. Training specifications of the ANN model determined that the error was $1 \mathrm{e}-5$ and the training data required 139 epochs. The simulation results obtained by the ANN coincided well with the experimental data. This narrow band of error measured throughout the groups for the modelled parameters was an indication of the robustness of the ANN. Models such as the one developed in this study allow plant operators to assess the expected plant effluent, given the quality of the waste stream at input locations.
\end{abstract}

Keywords: Activated Sludge Process, ANN, Paper and Pulp Effluent, Secondary Clarifier, Solid Flux

\section{Introduction}

\subsection{Background}

With the ever-increasing social awareness of environmental protection issues, proper operation and control of wastewater treatment plants (WWTPs) have come under scrutiny. The process industries are forced to adopt advanced techniques to improve their global competitiveness due to the increased cost of energy and increasingly strict environmental regulations. Recently, long-range predictive control algorithms are being considered by industries to improve the overall plant operability, energy efficiency, waste and effluent minimization, and control performance $^{1-9}$. Optimizing every stage of the WWTP demands systematic investigation and determination of control strategies ${ }^{10}$ that will lead to minimization of multiple objective criteria. Improper operation of a WWTP may bring about serious environmental and public health problems, as its effluent to a receiving water body can cause or spread various diseases to human beings.
Several algorithms $s^{9,11}$ and modeling approaches ${ }^{12,13}$ have been developed to tackle the complex technical problems associated with the control of industrial plants. In particular, artificial neural network (ANN)-based models have shown promising results in industrial wastewater treatment process and its performance evaluation ${ }^{14-24}$. Therefore, an improved performance and adherence to stringent standards for process effluents as well as minimized operational costs and environmental impacts, are needed for most WWTPs.

\subsection{Motivation}

In the recent years, neural networks (NN) have been proposed as a promising tool for identifying empirical process models from process data ${ }^{4,25}$. NN are very useful because of their ability to model complex non-linear processes, even when process understanding is unlimited. These neural network models can be used for prediction, provided the process correlation structure does not change. The main objective in using neural network modeling is to accurately

*Author for correspondence 
predict steady-state or dynamic process behavior in order to monitor and improve process performance. Given their inherent ability to approximate any non-linear continuous function without requiring any prior knowledge, $\mathrm{NN}$, in the last few years, have increasingly deserving the attention of the control community, leading to the implementation of several neural-based control strategies s $^{21,26-28}$. Although NNs are obtained by fitting data, some notable differences exist between NNs and typical empirical models. Recent developments have provided significant insights into the nature of neural learning, through the proof of mathematical properties ${ }^{29,30}$ and examinations of the relationships between neural learning and mathematical approximation theor $\mathrm{y}^{31,32}$. Hence, it was thought of worthwhile to develop ANN-based predictive model to approximate the thickener area of a secondary settling tank. Models such as the one developed in this study allow plant operators to assess the expected plant effluent, given the quality of the waste stream at input locations.

\subsection{Related Works}

A three-stage analysis approach integrating fuzzy logic, genetic algorithms, and neural networks was employed for modeling industrial WWTPs ${ }^{15}$. This approach was used for generating a representative state function, searching a set of multi-objective control strategies, and automatically tuning the fuzzy control rule base used for controlling a treatment plant. The developed model was successfully applied on a case study in Taiwan. An intelligent wastewater treatment concept aided by two sets of neural networks with the aim of controlling the plant in terms of previously selected parameters was proposed ${ }^{6}$. ANN models was developed to predict the effluent concentrations of biochemical oxygen demand (BODs) and suspended solids (SS) for WWTP which cover a range of data for training and testing purposes ${ }^{18}$. Artificial neural networks were developed through the use of universal approximators (sigmoidal MLP networks) or linear combinations of expanded input variables (monomers at FLN) for modeling the inner mapping between input and output variables ${ }^{33}$.

\subsection{Problem Statement and Solution Phase}

Combining models to improve prediction accuracy was an idea by Jones et al. ${ }^{34}$ which demonstrated how modeling results can be used to guide the design of monitoring protocols and monitoring results can, in turn, be used to refine models. The primary goal of this research study is to construct accurate models that predict the thickener area of the secondary settling tank using NNs as they have been widely used for complex processes that are poorly described by first principle models such as wastewater biological treatment systems ${ }^{5}$. The study was conducted in three phases to build-up a methodology for the design of secondary clarifier pertaining to paper and pulp mill using ANN approach as no one applies this technique in paper and pulp making industries. During the first phase of work, a methodology has been proposed to predict the performance of secondary clarifier by correlating process control parameters using feed-forward NN model. In the second phase of the work, experiments were conducted on paper and pulp mill wastewater in the stationary phase of the microbial growth. To fully evaluate the thickening characteristics of an activated sludge, the zone settling velocity (ZSV) was measured at several concentrations of solids. In the third phase, an ANN-based predictive model was developed to predict the performance of secondary clarifier by correlating process control parameters obtained from experiments end result, from which for any value of $C_{u^{\prime}}, C_{o}, R$ and $\theta_{c^{\prime}}$, the area of the secondary clarifier can be determined by using the ANN model.

The final optimized model was approved by an Indian pulp and paper manufacturer M/s. Seshasayee Paper and Boards Ltd, a South Indian based paper making industry situated in Erode which signalled the practical compatibility of this research project. The ANN approach helped the WWTP engineers of the above paper manufacturing industry to be glad about the performance enhancement of the secondary clarifier, which was possible because of the optimized WWTP design. The details of this endeavour are briefly presented in this research article. This ANN technique provides a new direction to the WWTP designer, especially for new design and new application, without immediately going for physical trial. This attempt has been done with the intention of helping the pulp and paper industry to sustain in the competitive global market.

\section{Overview and Contributions}

The efficiency of WWTP strongly depends on the inlet flow and the component concentrations of the effluent. The forecasting of WWTP load provides promising opportunities to accomplish relevant operational actions automatically or manually and permits the use of more realistic estimations of future disturbances ${ }^{8}$. The 
non-linearity of WWTP operation could be taken into account for calculating the predicted output because of the available estimates of the model, which depend on the input flow rate and concentration. Every specific plant has its own process environmental conditions and process operations, making it difficult to develop an accurate general model. In recent years, neural networks have been successfully applied to various biochemical processes ${ }^{11,14,23}$. They have a distinct ability to model non-linear dynamic systems without requiring a structural knowledge of the process to be modelled. NNs can map a set of input patterns onto a corresponding set of output patterns on the basis of historical data. The ANNbased models are widely applied for WWTP in global scenario $^{1,8,18-20,26,34}$. This paper presents predictive models based on the concept of ANN, a widely used application of artificial intelligence that has shown fairly a promise in a variety of applications in paper making process identification $^{7,11,18,33}$.

\section{ANN Model Development}

An ANN is a computational tool capable of estimating and predicting engineering properties that are a function of many variables and parameters. ANNs have the ability to learn from existing data and to be adopted for mapping a set of input parameters into a set of output parameters, without knowing the intricate relationship among them. One of the most common types of NN is the feed-forward, where information is transmitted only in a forward direction ${ }^{3,18}$. In this study, a feed-forward algorithm ${ }^{5}$, consisting of one input layer, one hidden layer and one output layer, all connected with no feedback connections, has been applied. The weighted sums of the inputs are transferred to the hidden neurons, where it is transformed by using an activation function. The outputs of the hidden neurons, in turn, act as inputs to the output neuron where it undergoes another transformation. The output of a feed-forward NN with one hidden layer and one output $\mathrm{NN}$ is given by Equation (1).

$$
\mathrm{I}_{\mathrm{ki}}=\mathrm{w}_{\mathrm{ijk}} \mathrm{O}_{\mathrm{ki}}+\mathrm{w}_{\mathrm{iok}}
$$

Where

$$
\begin{aligned}
\mathrm{w}_{\mathrm{ijk}}, \mathrm{O}_{\mathrm{ki}} & - \text { weight of the link between } \mathrm{i}^{\text {th }} \text { input and } \mathrm{j}^{\text {th }} \\
& \text { hidden neuron } \\
\mathrm{k} & \text { - number of input neurons } \\
\mathrm{w}_{\mathrm{iok}} & \text { - weight of the link between } \mathrm{j}^{\text {th }} \text { hidden neuron } \\
& \text { and } \mathrm{o}^{\text {th }} \text { output }
\end{aligned}
$$

A linear activation function was selected for the output neuron because it is appropriate for continuous valued targets. The learning abilities of multi-layer feed-forward neural networks depend on the types of activation functions ${ }^{35}$. The two important stages in ANNbased model development are model training and testing the trained model as illustrated in Figure 1. The training of an ANN-based model requires input data.

\subsection{Selection of Model Input and Output}

Output(s) are selected on the basis of operational needs, relevant literature and data availability ${ }^{4}$. ANN models are trained by minimizing the errors between the predicted and actual values of model output variables. However, this technique yields better results when a single output is modelled. Once the model output has been selected, model input is selected from the available variables. Model input selection is based on the existence of a known or assumed relationship among the output variables, relevant literature and data availability. In this study, recirculation ratio $(\mathrm{R})$, underflow concentration $\left(\mathrm{C}_{\mathrm{u}}, \mathrm{g} / \mathrm{L}\right)$ and limiting solid flux $\left(G_{L}, \mathrm{~kg} / \mathrm{m}^{2} \mathrm{~h}\right)$ were selected as input variables. Area of secondary clarifier required per unit flow (A/Q) was selected as an output variable.

\subsection{Selection and Organization of Data Patterns}

The modelling data sets can be constructed after the model input and output variables are identified. Each data pattern or record should initially be examined for erroneous entries, outliers and blank entries ${ }^{2,22-24,27}$. Outlier detection involves a high degree of subjectivity, for example, all values that are outside a range of \pm 2 standard deviation from the mean of a variable may be excluded from the data set. Alternatively, scatter plots of each variable can be used to detect outlier values. Data patterns that contain questionable data should be removed and a record of the removed patterns should be maintained for future reference and analysis. There are two important stages in model development using an ANN as discussed in preceding section: The first stage is training the model and the second stage is testing of trained model. Training of an ANN requires input data, namely, $R, C_{u}$ and $G_{L}$. To develop the model for the thickener area of secondary settling tank, the parameters $\mathrm{R}, \mathrm{C}_{\mathrm{u}}, \mathrm{C}_{\mathrm{o}}$ and $\mathrm{A} / \mathrm{Q}$ were correlated. The models were developed for various $\theta_{c}(5-13$ days) and $\mathrm{R}(0.25-1.0)$ values. 


\subsection{Feed-forward Architecture}

Models considering the main treatment units separately and estimating multiple parameters have not been successfully developed yet. In-spite of some successful practical applications, there is still no all-inclusive procedure or method to design such intelligent controllers by far because of its semi-empirical nature. The idea behind using feed-forward $\mathrm{NN}$ is to formulate a model which could find the results of $A / Q$ under any different parameters of $\mathrm{R}, \mathrm{G}_{\mathrm{L}}$ and $\mathrm{C}_{\mathrm{u}}$ in a specified range. This network is static. The input vectors are considered to be concurrent. In short, the NN required here is made to be simple by considering the network fed with the single input vector.

In this proposed network model, the inputs are presented as a matrix of concurrent vectors and the weights are updated only after all the inputs are fed which is called as batch mode $3,8,10,11,23,30$. Once the NN model has been created, the analysis shall be done for different values of $R, G_{L}$ and $C_{u}$. With the trained network, any change in the input will be sensitized with utmost care by the neural network and the results could be evaluated for a huge data in a shorter duration with greater accuracy ${ }^{7}$. Network training is a process by which the connection weights and biases of the ANN are adopted through a continuous process of simulation by the environment in which the network is embedded. The primary goal of training is to minimize an error function by searching for a set of connection strengths and biases that cause the ANN to produce outputs that are equal or close to targets ${ }^{4}$. The model architecture, training method and training rates are determined using a trial-anderror approach. The amount by which each connection weight is adjusted depends on the learning rate $(\eta)$, the momentum value $(\mu)$, the epoch's size $(\varepsilon)$, the derivative of the transfer function and the node output. Training was stopped when there was no further improvement (reduction in root mean square error (RMSE)) in the forecasts obtained by using an independent test data set. This value, which is the model predicted value, was compared to the correct value for the given patterns and the connection weights were modified to decrease the sum of the squared error. The output signal produced was then compared with the desired output signal with the aid of an error (mean square error) function shown in Equation (2).

$$
E(t)=\frac{1}{2} \sum\left(d_{j}(t)-y_{j}(t)\right)^{2}
$$

Where

$\mathrm{E}(\mathrm{t})$ - global error function at discrete time, $\mathrm{t}$

$\mathrm{y}_{\mathrm{j}}(\mathrm{t})$ - predicted network output at discrete time, $\mathrm{t}$

$d_{j}(t)$ - desired network output at discrete time, $t$

In this study, ANN models were trained for each $\theta_{c}$ of $5,7,9,11$ and 13 days and for the $\mathrm{R}$ values of 0.25 , $0.4,0.55,0.7,0.85$ and 1.0. After all the data were trained, new sets of data were tested. Among the 4230 data samples, 2230 were used as training data and the remaining 2000 as testing data. The computation of regression coefficient, i.e., $\mathrm{R}^{2}=0.992$ for the train data and test data was obtained from Minitab 16, which exhibits the robustness of the ANN model.

\section{Materials and Methods}

\subsection{Effluent Source}

Effluent samples were obtained from Seshasayee Paper Mill, Erode, Tamilnadu, an integrated pulp and paper industry based in South India. The paper and pulp effluent from the outlet of the primary settling tank was used for the investigation. The sample was collected using a sterile plastic container and was stored at $4^{\circ} \mathrm{C}$ until required.

\subsection{Settling Studies}

Wastewater is first treated in settling tanks where the solids, which settle, are removed ${ }^{36}$. The partially treated wastewater is then processed in a biological treatment plant, where micro-organisms degrade the organic water to biomass (sludge) and water (plus gases). Further settling follows. This biological treatment is by far the most common treatment process for municipal and industrial wastewater ${ }^{33,34}$. More precise flow rates can be determined from industry using continuous processes than from industry using batch processes. Each industry is individual, and a wastewater survey is obligatory to determine flow rates and pollution load. It is desirable to develop a flow duration curve and also a pollution load duration curve at specific points along the waste streams. Experiments were conducted on paper and pulp mill wastewater with mean cell residence time $\left(\theta_{c}\right)$ values of $5,7,9,11$, and $13 \mathrm{~d}$ in the stationary phase of the microbial growth curve. Batch reactors (20 L capacity) were run with a food to micro-organism $(\mathrm{F} / \mathrm{M})$ ratio of 0.2 (range: $0.2-0.6)$ in the stationary phase. The desired $\theta_{c}$ was maintained (i.e., $\theta_{c}=\frac{V}{Q} Q_{w}$ ) by wasting a portion of the mixed 
liquor $\left(Q_{w}\right)$ from the reactor. To fully evaluate the thickening characteristics of an activated sludge, the zone settling velocity (ZSV) were measured at several concentrations of solids $s^{38,39}$. Therefore, after attaining steady state conditions, column settling tests were conducted to generate the settling flux data. Sludge samples $(2-20 \mathrm{~g} / \mathrm{L})$ were added in $1 \mathrm{~g} / \mathrm{L}$ increments to a glass column $(22.5 \mathrm{~mm}$ diameter, $650 \mathrm{~mm}$ height), and the interface height was recorded as a function of time.

Settling curves were plotted connecting the solids concentration and interface height for $\theta_{c}$ values of 5-13 d in the stationary phase. The slope of the linear portion of each batch settling curve was determined graphically, and was designated as the ZSV associated with the corresponding solids concentration (Figure 1). The gravity solid flux was determined as the product of the ZSV and the corresponding solids concentration (Figure 2). Each value of $\mathrm{G}_{\mathrm{L}}$ represents the gravity settling flux per unit area of the clarifier that would be expected to occur at the corresponding activated sludge concentration.

\subsection{Secondary Clarifier Design by Solid Flux Analysis}

The secondary clarifier plays an important role in achieving the strict efficiency standards of WWTPs. The design and operation of the secondary clarifier are commonly based on solid flux theory $y^{3,27,37,38,39}$. The values of the initial suspended concentration $\left(\mathrm{C}_{\mathrm{o}}\right)$ and the area of the secondary clarifier required per unit flow (A/Q) were determined for each combination of underflow concentration $\left(C_{U}\right.$, in $\left.g / L\right)$, limiting solid flux $\left(G_{L}\right.$, in $\left.\mathrm{kg} / \mathrm{m}^{2} \mathrm{~h}\right)$, and recirculation ratio $(\mathrm{R})$ values from the material balance Equations:

$$
\begin{gathered}
\mathrm{C}_{\mathrm{o}}=\frac{\mathrm{R}}{1+\mathrm{R}} \mathrm{C}_{\mathrm{u}} \\
\frac{\mathrm{A}}{\mathrm{Q}}=\frac{\mathrm{RC}_{\mathrm{u}}}{\mathrm{G}_{\mathrm{L}}}
\end{gathered}
$$

\section{Case Study}

\subsection{Performance Evaluation of ANN Model}

Larger networks take more time to train and require more data to efficiently estimate the connection weights. A general relationship between the inputs and outputs contained in the training data set can be obtained after a network has been trained ${ }^{4}$. Consequently, for realtime forecasting applications, it is advisable to retain the model as new data become available. The most widely used performance measures for ANN models are RMSE in Equation 5 and the average absolute error (AAE) in Equation 6 between the actual and predicted values.

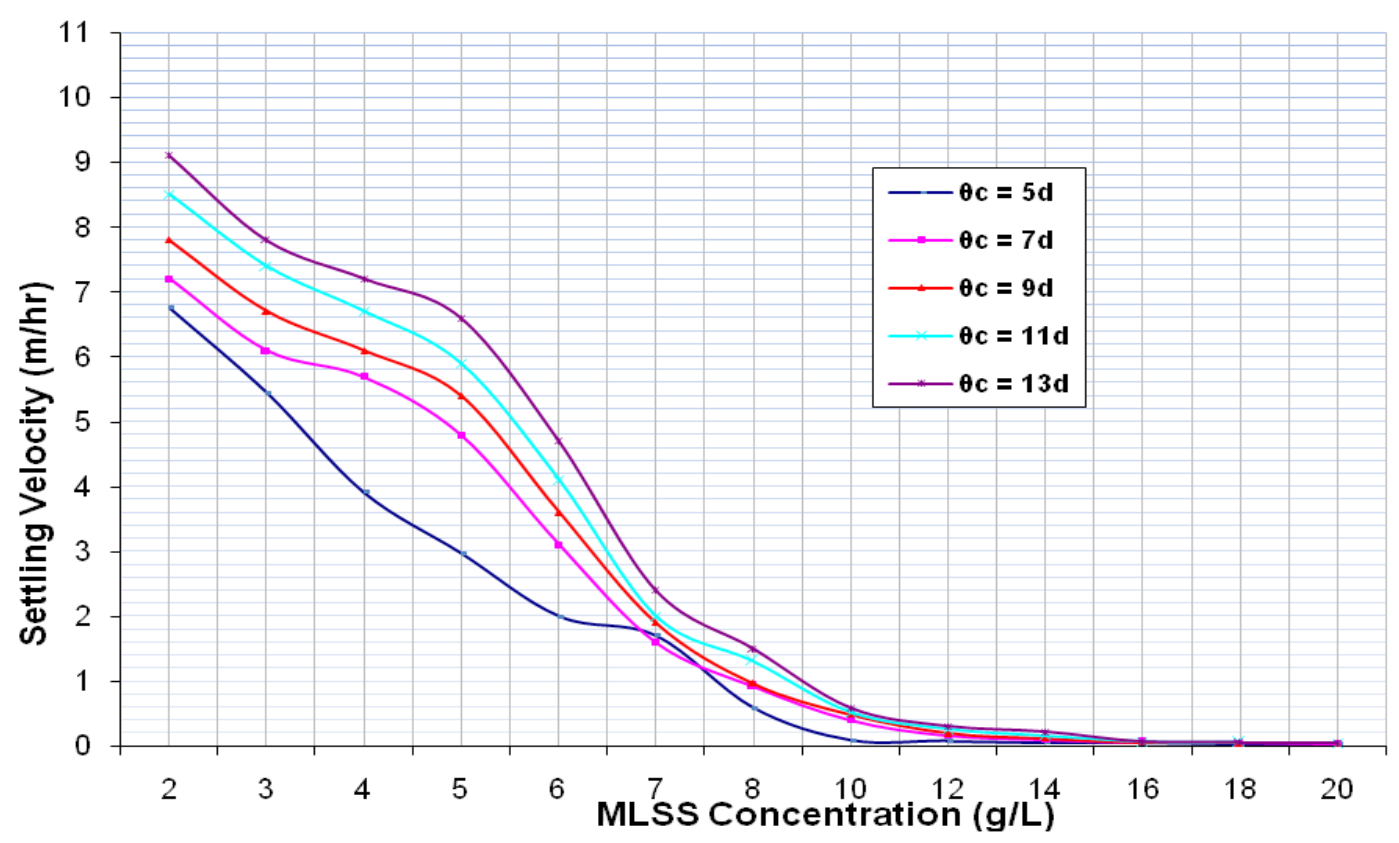

Figure 1. Settling velocity curve for $\operatorname{MCRT}\left(\theta_{c}\right)$. 


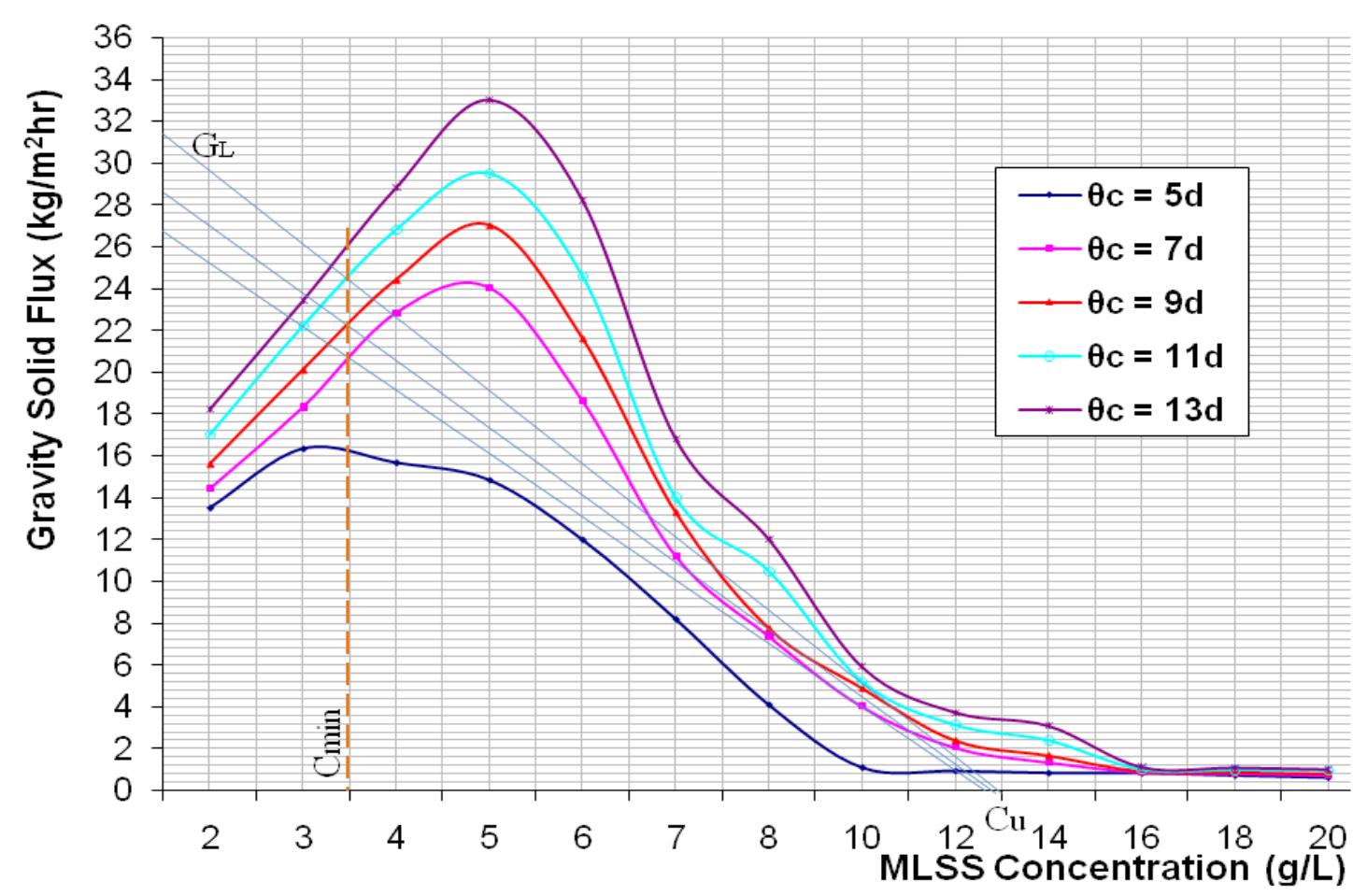

Figure 2. Solid flux curve for $\operatorname{MCRT}\left(\theta_{c}\right)$.

$$
\begin{aligned}
\text { RMSE } & =\sqrt{\frac{\sum_{i=1}^{n}\left(t_{i}-o_{i}\right)^{2}}{n}} \\
A A E & =\frac{1}{n} \sum_{i=1}^{n}\left(t_{i}-o_{i}\right)
\end{aligned}
$$

Where

$t_{i}$ - target (actual) value

$\mathrm{o}_{\mathrm{i}}$ - predicted value

$\mathrm{n}$ - number of records

In this study, it is found that $\mathrm{RMSE} \approx 4.53 \%$ and $\mathrm{AAE} \approx 0.72 \%$ for all groups. This narrow band of error measured throughout the groups for the modelled parameters was an indication of the robustness of the $\mathrm{ANN}^{31}$. The training records contain sufficient patterns to allow the ANN model to adequately mimic the underlying relationships between the output and input variables. The test records were not applied to the networks during training, but after the training was completed, they were used to test the performance of the trained network for its forecasting ability of output variables. Representative data for training and test data for the developing ANN model are given in Table 1.

The training time varied between 0.009 and $22.6 \mathrm{~s}$ (Table 2). The test data were applied to the network for each value of $\theta_{c}$ and $R$. The simulation results obtained by

the ANN coincided well with the experimental data. For a given value of $\theta_{c}$ and different values of $R=0.25-1.0$, the feed-forward NN was trained and the trained network was tested with the test data. The comparison of test data with the train data for $\theta_{c}=13$ days, $R=0.25-1.0$ is given in Figure 3(a-f). Similar results were obtained for other $\theta_{c}$ values.

Training specifications of the ANN model for $\theta_{c}=11$ days, $\mathrm{R}=0.4$ are given in Figure 4 from which it could be determined that the error was $1 \mathrm{e}-5$ and the training data required 139 epochs. Results were similarly obtained for the remaining ANN data. The epochs required for the trained feed-forward network varied between 100 and 500 . The accuracy of the results was in the range of $1 \mathrm{e}-3$. To develop the ANN model for the thickener area of the secondary clarifier ${ }^{3,26}$, the parameters $A / Q, C_{u}, C_{o}$, and $\mathrm{R}$ were correlated. To evaluate the model performance, actual values of A/Q in the testing data sets were compared to the values predicted by the NN models.

The quality of match between the ANN-modeled and experimentally measured values were determined by regression analysis for $\theta_{c}=5$ days, $R=0.4$ (Figure 5 ), which reveals that the ANN models resulted in a good fit for the experimentally measured A/Q. Similar results were obtained for other $\theta_{c}$ 's and $R=0.25,0.55,0.7,0.85$ and 1.0. 
Table 1. Representative data for training and testing ANN model $\left(\theta_{c}=7\right.$ day, $\left.R=0.4\right)$.

\begin{tabular}{|c|c|c|c|c|c|c|c|c|c|c|c|c|}
\hline \multirow{2}{*}{$\begin{array}{l}\text { Trial } \\
\text { No }\end{array}$} & \multicolumn{6}{|c|}{ ANN train data } & \multicolumn{6}{|c|}{ ANN test data } \\
\hline & $\mathrm{C}_{\mathrm{U}}$ & $\mathrm{G}_{\mathrm{L}}$ & $\mathrm{C}_{\mathrm{O}}$ & $\mathrm{E}(\mathrm{A} / \mathrm{Q})$ & ANN A/Q & Error & $\mathrm{C}_{\mathrm{U}}$ & $\mathrm{G}_{\mathrm{L}}$ & $\mathrm{C}_{\mathrm{O}}$ & $\mathrm{E}(\mathrm{A} / \mathrm{Q})$ & ANN A/Q & Error \\
\hline 1 & 10 & 29.1 & 2.86 & 0.1376 & 0.1375 & $1 \mathrm{E}-04$ & 10.1 & 28.7 & 2.88 & 0.1407 & 0.1408 & $-1 \mathrm{E}-04$ \\
\hline 2 & 11 & 22.2 & 3.14 & 0.1982 & 0.1982 & 0 & 11.3 & 21.1 & 3.23 & 0.2142 & 0.2142 & 0 \\
\hline 3 & 12 & 19.3 & 3.43 & 0.2486 & 0.2487 & -0.0001 & 12.6 & 18.65 & 3.6 & 0.2792 & 0.2792 & 0 \\
\hline 4 & 13 & 17.2 & 3.71 & 0.302 & 0.302 & 0 & 13.8 & 14 & 3.94 & 0.3942 & 0.3943 & $-1 \mathrm{E}-04$ \\
\hline 5 & 14 & 13.3 & 4 & 0.421 & 0.4211 & $-1 \mathrm{E}-04$ & 14.1 & 13 & 4.03 & 0.4338 & 0.4338 & 0 \\
\hline 6 & 15 & 10.4 & 4.29 & 0.576 & 0.5769 & -0.0009 & 15.3 & 9.3 & 4.37 & 0.658 & 0.6581 & $-1 \mathrm{E}-04$ \\
\hline 7 & 16 & 8.1 & 4.57 & 0.79 & 0.7901 & $-1 \mathrm{E}-04$ & 16.6 & 7.35 & 4.74 & 0.9034 & 0.9034 & 0 \\
\hline 8 & 17 & 6.7 & 4.86 & 1.014 & 1.0149 & -0.0009 & 17.8 & 6 & 5.09 & 1.1866 & 1.1867 & $-1 \mathrm{E}-04$ \\
\hline 9 & 18 & 5.9 & 5.14 & 1.22 & 1.2203 & -0.0003 & 18.2 & 5.7 & 5.2 & 1.2771 & 1.2772 & $-1 \mathrm{E}-04$ \\
\hline 10 & 19 & 4.9 & 5.43 & 1.54 & 1.551 & -0.011 & 19.4 & 4.55 & 5.54 & 1.7054 & 1.7055 & $-1 \mathrm{E}-04$ \\
\hline 11 & 20 & 4.1 & 5.72 & 1.948 & 1.95 & -0.002 & 20.3 & 3.8 & 5.8 & 2.1368 & 2.1368 & 0 \\
\hline 12 & 21 & 3.45 & 6 & 2.43 & 2.4348 & -0.0048 & 21.8 & 2.8 & 6.23 & 3.1142 & 3.1143 & $-1 \mathrm{E}-04$ \\
\hline 13 & 22 & 2.7 & 6.29 & 3.25 & 3.2593 & -0.0093 & 22.7 & 2.4 & 6.49 & 3.7833 & 3.7833 & 0 \\
\hline 14 & 23 & 2.3 & 6.57 & 4 & 4 & 0 & 23.4 & 2.15 & 6.8 & 4.427 & 4.4279 & $-9 \mathrm{E}-04$ \\
\hline 15 & 23.5 & 2.2 & 6.7 & 4.2727 & 4.2727 & 0 & 23.6 & 2.1 & 6.83 & 4.5523 & 4.5524 & $-1 \mathrm{E}-04$ \\
\hline
\end{tabular}

Table 2. Training and simulation time for various MCRT $\left(\theta_{c}\right)$.

\begin{tabular}{|c|c|c|c|c|c|c|c|c|c|c|c|c|}
\hline \multirow[b]{2}{*}{ 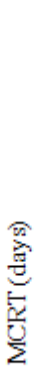 } & \multicolumn{2}{|c|}{$\mathrm{R}=0.25$} & \multicolumn{2}{|c|}{$\mathrm{R}=0.40$} & \multicolumn{2}{|c|}{$\mathrm{R}=0.55$} & \multicolumn{2}{|c|}{$\mathrm{R}=0.70$} & \multicolumn{2}{|c|}{$\mathrm{R}=0.85$} & \multicolumn{2}{|c|}{$\mathrm{R}=1.0$} \\
\hline & 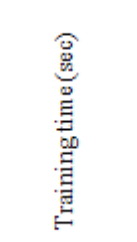 & 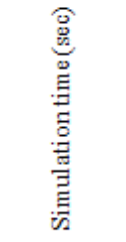 & 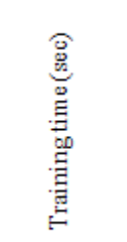 & 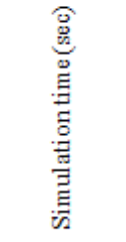 & 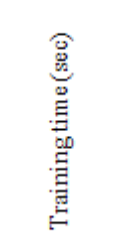 & 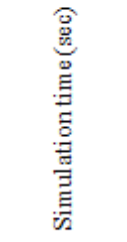 & 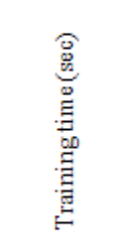 & 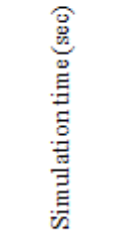 & 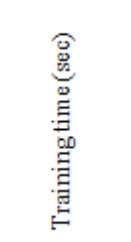 & 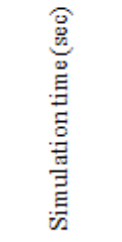 & 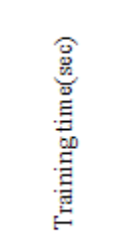 & 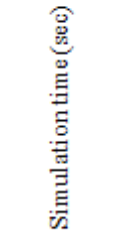 \\
\hline 5 & 7.117237 & 0.01788 & 2.671431 & 0.011593 & 2.560292 & 0.017478 & 3.738856 & 0.013662 & 4.907897 & 0.013191 & 10.789640 & 0.013403 \\
\hline 7 & 7.950571 & 0.093089 & 3.719618 & 0.013330 & 5.951715 & 0.016978 & 11.398533 & 0.096304 & 3.697090 & 0.011580 & 5.537524 & 0.012748 \\
\hline 9 & 1.8966588 & 0.011831 & 4.704291 & 0.012899 & 1.947908 & 0.012900 & 9.590542 & 0.011016 & 7.7259905 & 0.013465 & 22.602292 & 0.010564 \\
\hline 11 & 16.212307 & 0.136313 & 12.14948 & 0.142725 & 3.113203 & 0.010987 & 7.874811 & 0.014416 & 4.579651 & 0.14291 & 2.957643 & 0.016157 \\
\hline 13 & 13.173632 & 0.012431 & 8.640731 & 0.009889 & 2.532787 & 0.013450 & 8.753423 & 1.075456 & 4.140551 & 0.011343 & 6.473655 & 0.016195 \\
\hline
\end{tabular}

Figure 6 shows the representative error distribution keeping $\mathrm{R}=0.7$ and $\theta_{\mathrm{c}}=5$ days for experimental $\mathrm{A} / \mathrm{Q}$ and ANN A/Q.

\subsection{Evolution of the Mathematical Model}

It should be noted that, theoretically, using an infinite number of independent variables to explain the change in a dependent variable would result in a high correlation coefficient $\left(\mathrm{R}^{2}\right)$ of 1 for the modelling data sets. In other words, the $\mathrm{R}^{2}$ value can be manipulated and should be assumed. The adjusted $\mathrm{R}^{2}$ value ${ }^{40}$ can be used as an attempt to correct this shortcoming, because it will not always increase when additional model parameters are added. In contrast to $\mathrm{R}^{2}$, the adjusted $\mathrm{R}^{2}$ increases only if the additional model parameters improve the regression results significantly in order to compensate for the increase in regression degrees of freedom. Nevertheless, there is no similar statistical parameter to perform reliable 

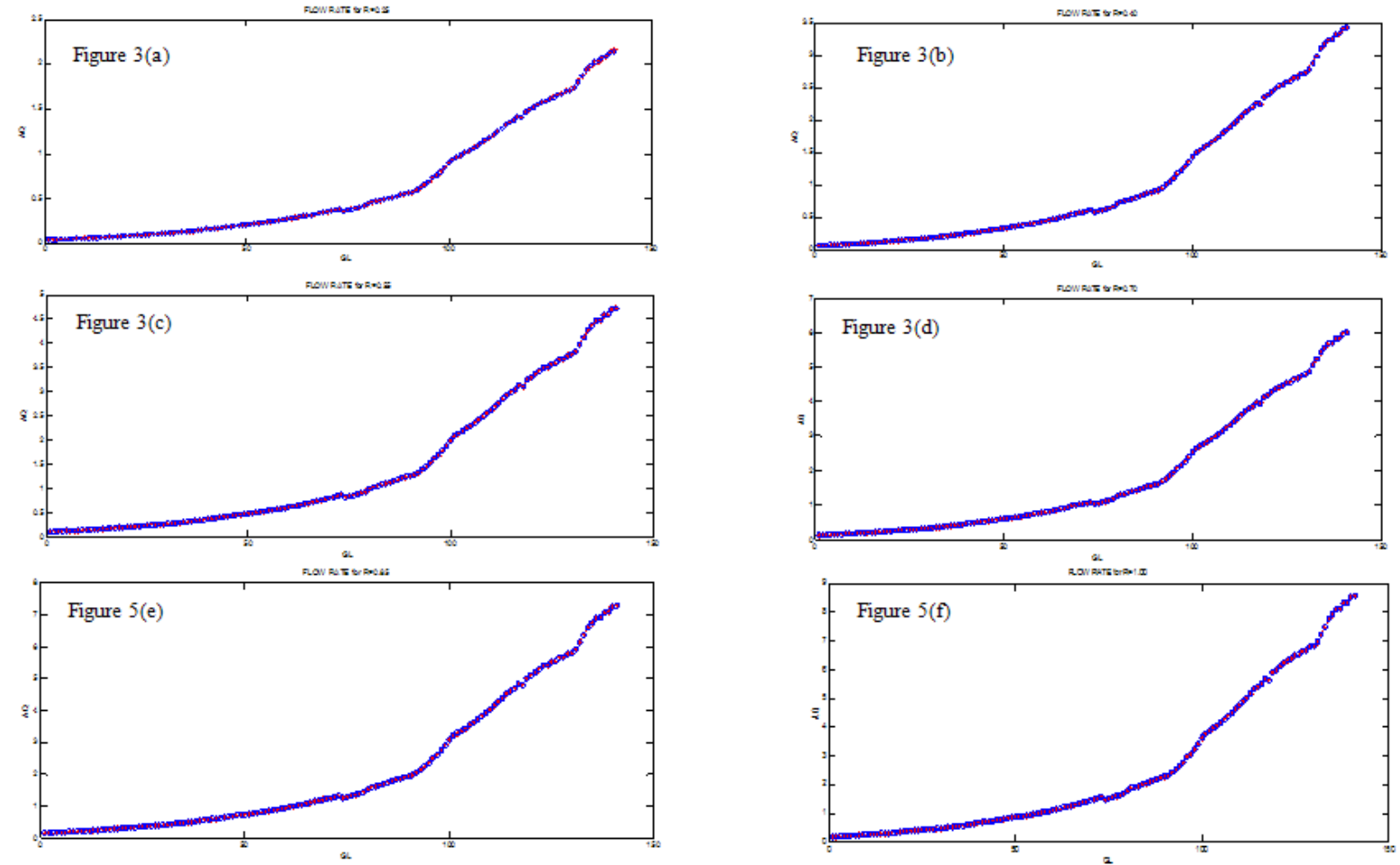

Figure $3(\mathbf{a}-\mathbf{f})$. Comparison of test data with the train data for $\theta_{c}=13$ days.

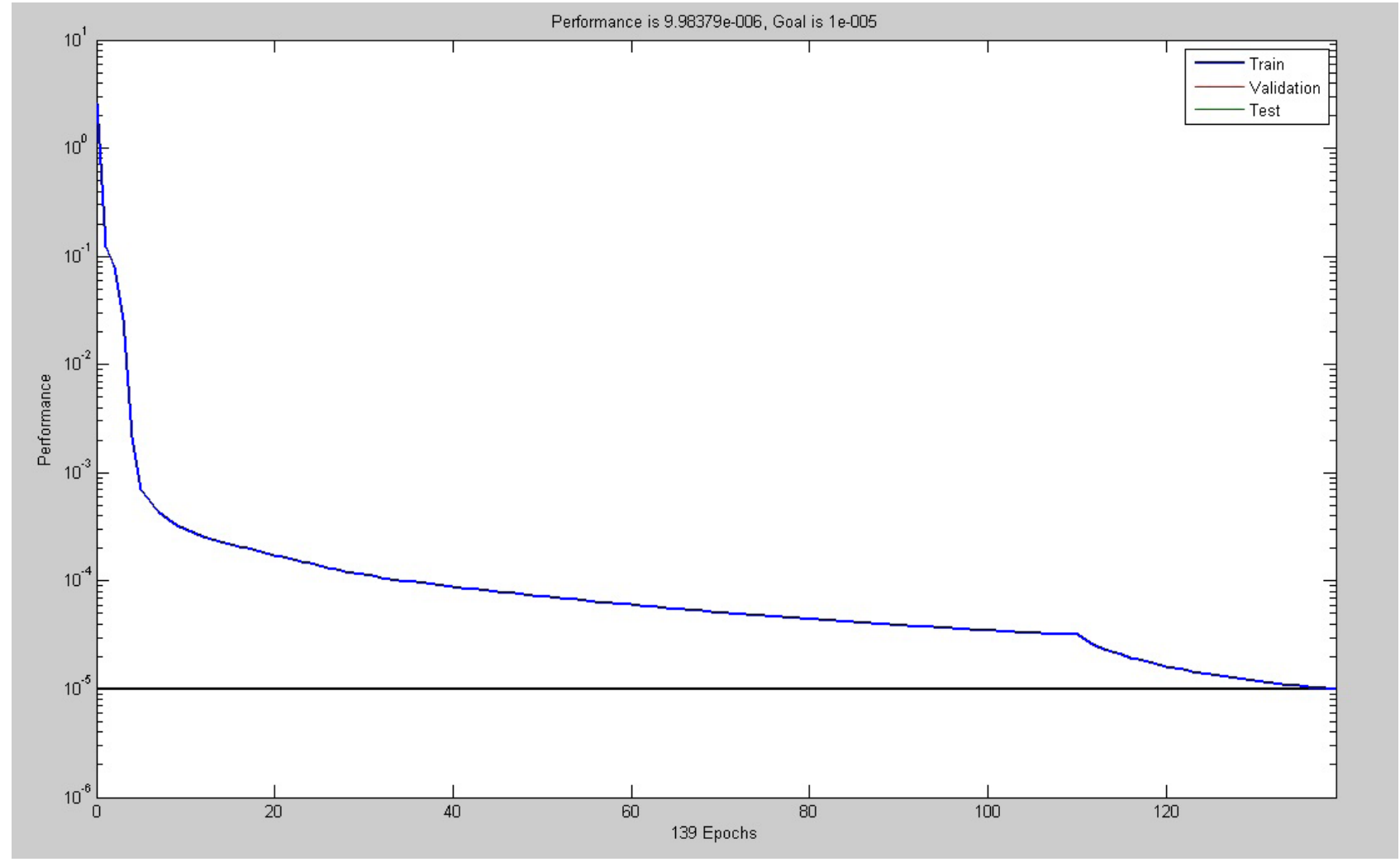

Figure 4. Training specifications of $A N N$ model for $\theta_{c}=11$ days, $\mathrm{R}=0.4$. 


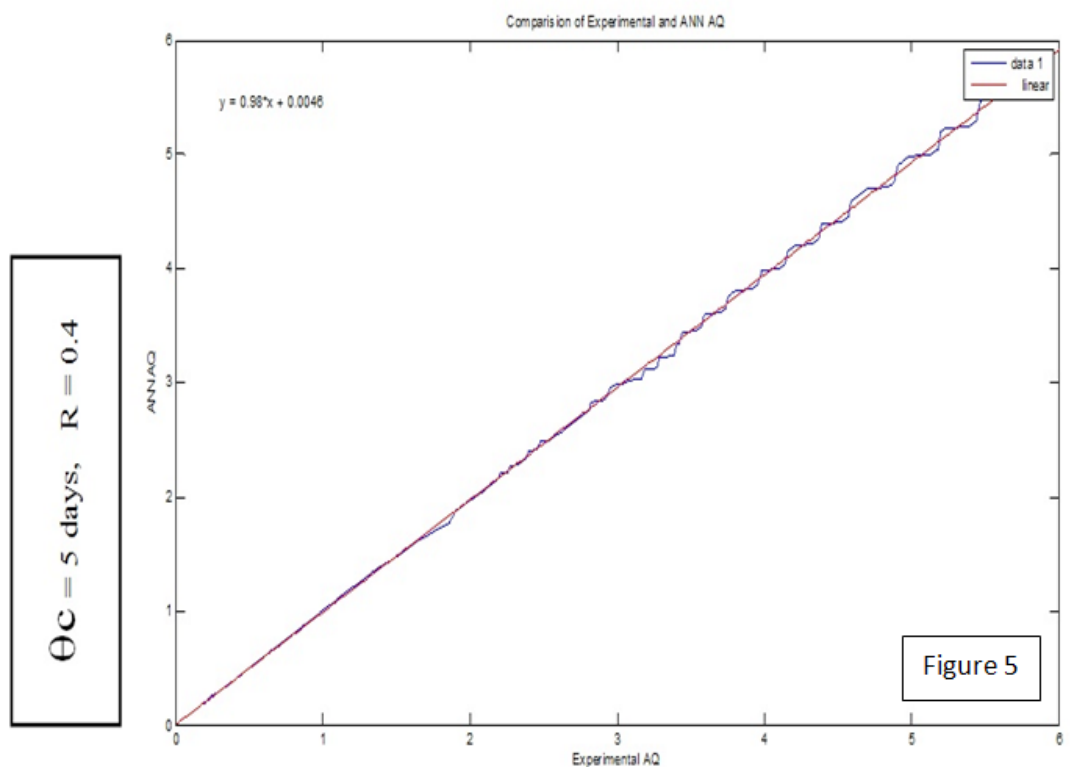

Figure 5. Match between experimental versus ANN model of thickener area of secondary clarifier (A/Q) for $\theta_{c}=5$ day.

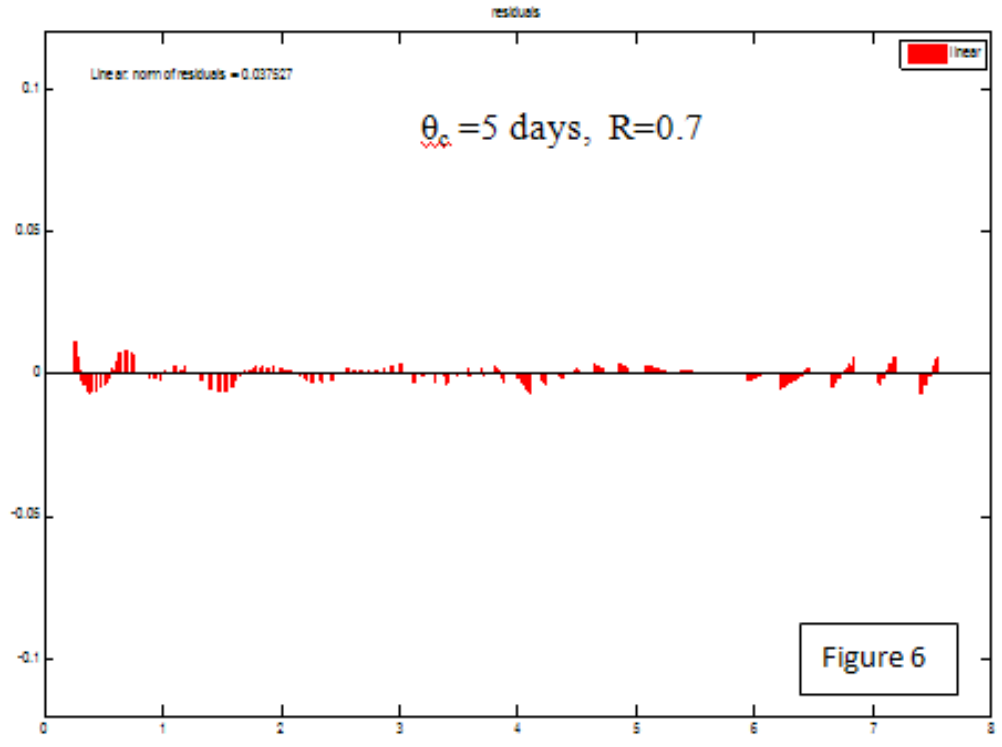

Figure 6. Error distribution of A/Q between experimental and ANN.

comparative analyses of the predictive performances of NN models and the methods proposed in the literature usually lead to contradictory results. The comparative analysis of statistical and NN models are based on $\mathrm{R}^{2}$ values estimated from the validation (and test) data sets. The quality of match between the ANN model values and experimentally measured values was verified with the mathematical model using SPSS software (Ver.15.0). Mathematical model for thickener area of secondary settling tank was obtained by correlating the parameters $\mathrm{R}, \mathrm{C}_{\mathrm{u}}, \mathrm{C}_{\mathrm{o}}$ and $\mathrm{A} / \mathrm{Q}$. The network was trained using different operational parameters ${ }^{4}$ and the findings indicated that the developed ANN model provided high performance criteria $\left(R^{2} \approx 0.96\right)$. These models are depicted in Equations (7-12). 


\section{MATHEMATICAL MODELLING}

\section{FOR EXPERIMENTAL DATA}

$$
\begin{aligned}
\log (\mathrm{A} / \mathrm{Q})= & -2.967+2.405 \log \mathrm{C}_{\mathrm{u}}+1.505 \log \mathrm{C}_{\mathrm{o}} \\
& -1.097 \log \theta_{\mathrm{C}}, \mathrm{R}^{2}=0.917 \\
\log (\mathrm{A} / \mathrm{Q})= & -3.401+3.909 \log \mathrm{C}_{\mathrm{u}}+1.000 \log \mathrm{R} \\
& -1.097 \log \theta_{\mathrm{C}}, \mathrm{R}^{2}=0.918 \\
\log (\mathrm{A} / \mathrm{Q})= & -2.245+3.881 \log \mathrm{C}_{\mathrm{O}}+1.568 \log \mathrm{R} \\
& -1.097 \log \theta_{\mathrm{C}}, \mathrm{R}^{2}=0.913
\end{aligned}
$$

\section{MATHEMATICAL MODELLING}

\section{FOR ANN DATA}

$$
\begin{aligned}
\log (\mathrm{A} / \mathrm{Q})= & -3.018+2.553 \log \mathrm{C}_{\mathrm{u}}+1.505 \log \mathrm{C}_{\mathrm{O}} \\
& -1.225 \log \theta_{\mathrm{c}}, \mathrm{R}^{2}=0.968 \\
\log (\mathrm{A} / \mathrm{Q})= & -3.452+4.058 \log \mathrm{C}_{\mathrm{u}}+1.000 \log \mathrm{R} \\
& -1.225 \log \theta_{\mathrm{c}}, \mathrm{R}^{2}=0.969 \\
\log (\mathrm{A} / \mathrm{Q})= & -2.252+4.029 \log \mathrm{C}_{\mathrm{O}}+1.665 \log \mathrm{R} \\
& -1.225 \log \theta_{\mathrm{C}}, \mathrm{R}^{2}=0.964
\end{aligned}
$$

\section{Conclusion}

In the present study, two models based on ANN and experimental investigations were developed to predict the area of the secondary clarifier for unit flow for a major paper and pulp mill WWTP. The ANN models provided a robust tool for prediction in which the prediction error varied slightly and smoothly over the range of data sizes used in training and testing. Once the feed-forward architecture for the training data was created, the feed-forward $\mathrm{NN}$ architecture could be utilized for identifying the A/Q value for any given input data. The test data applied to the $\mathrm{A} / \mathrm{Q}$ values coincided very well with the experimental values. ANN has proven to be a very useful tool in overcoming some of the limitations of conventional mathematical models for effluent treatment plants because of their complex mechanisms, variability and dynamics. The secondary clarifier area can be designed using the models proposed in this study for any values of $\mathrm{C}_{u^{\prime}}, \mathrm{C}, \mathrm{R}$ and $\theta_{c}$. The predicted models give a rational approach to the design of a secondary clarifier. The developed models are shown to perform consistently well in the face of varying accuracy and size of input data. Using these models, the plant operators will be able to have an assessment of the expected plant effluent, given the quality of the waste stream at input locations.

\section{Acknowledgement}

The authors are grateful to Seshasayee Paper and Boards Ltd., a South Indian based paper and pulp mill for their caring technical acquaintance in undertaking the case study.

\section{References}

1. Yu RF, Chen HW, et al. Measurements of Wastewater True color by 4/6 Wavelength Methods and Artificial Neural Network. Environmental Monitoring \& Assessment. 2006; 118(1-3):195-209.

2. Yu RF, Cheng WP, et al. On-line monitoring of wastewater true color using digital image analysis and ANN. Journal of Environmental Engineering. ASCE. 2005; 131(1):71-9.

3. Liu Z, Mitani J, et al. A 3D shape classifier with neural network supervision. Int J Computer Applications in Technology. 2010; 38:134-43.

4. Dutta S, Parsons SA, et al. Development of an artificial neural network model for adsorption and photo catalysis of reactive dye on $\mathrm{TiO}_{2}$ surface. Expert Systems with Applications. 2010; 37:8634-8.

5. Saha PD, Dutta S. Mathematical modelling of biosorption of safranin onto rice husk in a packed bed column using artificial neural network analysis. Desalination and Water Treatment. 2012; 41:308-14.

6. Moreno-Alfonso N, Redondo CF. Intelligent waste-water treatment with neural-networks. Water Policy. 2011; 3:267-71.

7. Mingzhi H, Ma Y, et al. Simulation of paper mill wastewater treatment using a fuzzy neural network. Expert systems with Applications. 2009; 36(3) Part I:5064-70.

8. Maier HR, Dandy GC. Neural networks for the prediction and forecasting of water resources variables, a review of modeling issues and applications. Water Resources Research. 2000; 15(1):101-24.

9. Zhangand J, Morris A. Long Range Predictive Control of Nonlinear Processes Based on Recurrent Neuro-Fuzzy Network Models. Neural Comput \& Applic. 2000; 9:50-9.

10. Tränckner J, Franz T, et al. Dynamic optimization of WWTP inflow to reduce total emission. Water Sci and Technol. 2007; 56(10):11-8. 
11. Zeng GM, Qin XS et al. A neural network predictive control system for paper mill wastewater treatment. Engineering Applications of Artificial Intelligence. 2003; 16(2):121-9.

12. Hussain MA. Review of the Applications of Neural Networks in Chemical Process Control - Simulation and On-line Implementation. Artificial Intelligence in Engineering. 1999; 13:55-68.

13. Baratti R, Cannas B, et al. Automated Recurrent Neural Network Design to Model the Dynamics of Complex Systems. Neural Comput \& Applic. 2000; 9:190-201.

14. Lee DS, Jeon CO, et al. Hybrid neural network modeling of a full-scale industrial wastewater treatment process. Biotechnology and Bioengineering. 2002; 78(6):670-82.

15. Chen WC, Chang NB, et al. Advanced hybrid fuzzy-neural controller for industrial wastewater treatment. Journal of Environmental Engineering. 2001; 127(11):1048-59.

16. Gontarski CA, Rodrigues PR, et al. Simulation of an industrial wastewater treatment plant using artificial neural networks. Computer and Chemical Engineering. 2000; 24:1719-23.

17. Hack M, Kohne M. Estimation of wastewater process parameters using neural networks. Water Science and Technology. 1996; 33:101-15.

18. Maged HM, Khalafallah MG, et al. Prediction of wastewater treatment plant performance using artificial neural networks. Environmental Modelling and Software. 2004; 19:919-28.

19. Hamoda MF, Al-Ghusain IA, et al. Integrated wastewater treatment plant performance evaluation using artificial neural networks. Water Science and Technology. 1999; 40:55-65.

20. Chen HW, Ning SK, et al. Optimizing the Monitoring Strategy of Wastewater Treatment Plants by Multi objective Neural Networks Approach. Environmental Monitoring and Assessment. 2007; 125:325-32.

21. Ruey-Fang Yu, Ho-Wen Chen, et al. Dynamic control of disinfection for wastewater reuses applying ORP / $\mathrm{pH}$ monitoring and artificial neural networks. Resources, Conservation and Recycling. 2008; 52:1015-21.

22. Ruey-Fang Yu, Shyh-Fang K, et al. Application of artificial neural network to control the coagulant dosing in water treatment plant. Water Science and Technology. 2008; 42(3/4):403-8.

23. Zhang Q, Stanley SJ. Real-time water treatment process control with artificial neural networks. Journal of Environmental Engineering. 1999; 125(2):153-60.

24. Bhat N, McAvoy T. Use of Neural Nets for Dynamic Modeling and Control of Chemical Process System. Computer and Chemical Engineering. 1990; (4/5):573-83.

25. Pollard JF, Broussard MR, et al. Process Identification Using Neural Networks. Computer and Chemical Engineering. 1992; 16(4):253-70.
26. Temeng H, Schenelle P, et al. Model Predictive Control of an Industrial Packed Bed Reactor Using Neural Networks. J Proc Control.1995; 5(1):19-28.

27. Tan Y, Cauwenberghe A. Non-Linear One Step Ahead Control Using Neural Networks: Control Strategy and Stability Design. Automatica. 1996; 32(12):1701-6.

28. Chen J. Systematic Derivations of Model Predictive Control Based on Artificial Neural Networks. Chemical Engineering Communications. 1998; 164:35-9.

29. Funahashi K. On the approximate realization of continuous mappings by neural networks. Neural Networks. 1989; 2:183-92.

30. Hornik K, Stinchcombe M, et al. Multilayer feed forward networks are universal approximators. Neural Networks. 1989; 2:359-66.

31. Utojo U, Bakshi BR. Neural Networks in Bio processing and Chemical Engineering, Appendix: Connections between Neural Networks and Multivariate Statistical Methods: An Overview, Academic Press. 1995.

32. Poggio T, Girosi F. Networks for approximation and learning. Proc IEEE. 1990; 9:1481-97.

33. Oliveira-Esquerre KP, Seborg DE, et al. Application of steady-state and dynamic modeling for the prediction of the BOD of an aerated lagoon at a pulp and paper mill Part II. Nonlinear approaches. Chemical Engineering Journal. 2004;105:61-9.

34. Jones CC, Acker SA, et al. Combining local- and largescale models to predict the distributions of invasive plant species. Ecology Applications. 2010; 20(2):311-26.

35. Daqi G, Genxing Y. Influences of Variable Scales and Activation Functions on the Performance of Multilayer Feed forward Neural Networks. Pattern Recognition. 2002; 36(4):869-78.

36. Abusam A, Keesman KJ. Dynamic modeling of sludge compaction and consolidation processes in wastewater secondary settling tanks. Water Environment Research. 2009; 81(1):51-6.

37. Bo-Chuan C, Shu-Liang L, et al. Development of a real-time control system with artificial neural network for automatic control of a continuous-flow sequencing batch reactor. Water Science and Technology. 2001; 44(1):95-104.

38. Saseetharan MK, Sheshadri S, et al. Modelling of SST for Domestic Activated Sludge. Journal of Institution of Engineers (India). 1997; 78:9-17.

39. Bhargava DS, Rajagopal K. Modelling for Zone Settling in Different Types of Suspended Materials. Water Research. 1990; 24:675-83.

40. Montgomery DC, Peck EA. Introduction to Linear Regression Analysis. New York: Wiley; 1992. 